\title{
New Learning Spaces? M-Learning's, in Particular the iPad's Potentials in Education
}

\author{
http://dx.doi.org/10.3991/ijim.v7i1.2398 \\ György Molnár Dr. \\ Budapest University of Technology and Economics, Budapest, Hungary
}

\begin{abstract}
The iPad is a very popular touchscreen tablet computer, which was introduced approximately two, two and a half years ago. It runs the MAC operating system making it suitable for different general and special uses. The paper focuses on the fact how the use of iPads can help education, make teaching and learning more efficient. In addition to the technical, infrastructural parameters, which are essential as much as the user's experience and it usability are concerned, the paper provides a few concrete applications as well. Today, the use of iPads is general either in everyday life, or in public education or tertiary education. The author analysis his experiences from the viewpoint of students, but also mentions applications useful for teachers. Students can use iPads with the appropriate applications in any stage of the learning process, e.g. using notes, course materials, schedules and assignments, cooperation, group assignments by collaboration. The paper also describes such solutions or respectively suggestions by means of which the monitoring of shared content and data can be realized by the teacher. A few professional applications (e.g. used by students of medicine, engineering and natural sciences) are also listed.
\end{abstract}

Index Terms-Learning support ICT devices; M-learning; IPad; Iphone; iOS; tablet PC

\section{INTRODUCTION}

The paper discusses a technological stage of the development of mobile communication having a significant influence on the future of our learning and knowledge, whose focus is a new dimension of informal learning. The new learning environment can be characterized by m-learning, which means a novel impulse in LLL forming a learning potential. iPads - a very rapidly developing family - have been chosen for presentation out of the mobile communication devices usable for supporting learning. The first part of the paper describes the physical, technical parameters of the device, then a few good practices of general and learning-oriented use. In the last part a few Hungarian and international practical examples in the field of concrete application are presented. The use of the iPad is the most widespread among teachers from the $\mathrm{Y}$ generation, but is relatively common among those from early $\mathrm{X}$ generation and previous generations. The statistical data showing the fast spread of Apple IOS devices as opposed to Microsoft Windows devices prove this fact.

The use of smartphones is now on everyday basis. The devices besides they use as phones function as multifunctional tools which can be helpful in navigation, internet browsing, global positioning, picture taking and video shooting. They also feature music playing and word processing functions. Most of the new generation phones are shipped with touch screens, GPS, support multimedia and operate on $3 G$ or $4 G$ (LTE) networks. The touch screens apply interactive multi-touch technology which has been developed since the 80 ' in order to display information and provide opportunities for visual communication. Jeff Han, the researcher of New York University was first to develop a functioning multi-touch screen that could be controlled by multiple fingers. The technology is based FTIR (Frustrated Total Internal Reflection) and computer based image processing.

Nowadays the use of iPad is common in everyday life, elementary and high schools, as well as at universities.

\section{BODY OF PAPER}

\section{A. M-learning}

The aim of this paper is to present a new, future dimension of informal learning, which will have a huge impact on education and is based on mobile communication technology.

This new learning space can be described as mlearning. It provides a new impulse to lifelong learning. From all devices applicable in education, this chapter will focus on a significant and fast developing segment, the iPads.

M-learning can be defined as access to course content by means of mobile devices and the related learning activity. Or rather the type of learning in the course of which an online CMS, LMS system can be accessed by means of a networked mobile communication device. This sort of use is provided by smart phones, and tablet PCs. Such a smart phone is Samsung GalaxyTab touchscreen device with Android Browser, which makes it possible to download optional web content and provides full scale multimedia. The intelligence of mobile communication devices limits the circle of downloadable content (web 2.0, flash, audio, and video). The smart phones available today use different operation systems, which makes compatibility a bit hard. Such a system is the long known Symbian, the Windows phone, the new Android, Apple IOS, the Bada and Blackberry platforms. The other main challenge is problem free content managements requires web feature optimized for mobile screens (unique CSS, optimized contents). In addition to these points of view, m-learning possibilities are increasingly used; furthermore, a great part of the developments focus on this direction, e.g. the official Moodle mobile client will soon be available to complete the well-known Moodle LMS system. The paper and our research work focuses on such a mobile communication device, the iPad, which is suitable for supporting m-learning [1], [2], [3]. 
The author primarily reflects his impressions from the students' points of view. The same he alludes to applications available to the teachers. The iPads preinstalled with the proper applications can be used by the students during the period of the learning process. Such are notes, excess to the learning materials, agendas and tasks, collaboration and group tasks which involve teamwork. The author introduces solutions and suggestions which allow the teacher to monitor content and information shared by the students. The author also reveals some applications used by different professions, i.e. medicine, engineering, technology.

\section{B. The iPad as a device}

The general characteristics and physical parameters of iPads are the following:

- 9.7” touch screen monitor $(1024 \times 768)$, in case of iPad3 with HD resolution up to $3.1 \mathrm{~m}$ pixels

- 10-hour battery

- Thinness: $8.8 \mathrm{~mm}$

- Weight: $613 \mathrm{~g}$

- Built-in Wi-Fi, 3G, and ultra-high speed4G LTE

- 16, 32, 64 GB inner memory

- MAC OS X operation system

- Built-in camera, in case of the latest, 3rd generation a 5MP camera

- Phone function, SIM card slot

- Types: iPad 1., 2., and 3.

- Fast booting and standby time

- 1080p HD video recording

The use of iPads has been increasing rapidly as opposed to the use of Microsoft-based systems in everyday, work and learning environments as well. MAC operation systems used by iPads are absolutely different from Microsoft platforms. In spite of their openness the file system of the operation system cannot be accessed to directly and fully, thus the direct basic file operations cannot be realized, which is common in the case of MS platforms. Special applications need to be used, such as iTunes, dropbox and teamviewer. So the MAC based iPad platform is not compatible with the most commonly used Microsoft operation system, which means that iPad applications cannot be used on MS platforms. However, Microsoft applications or respectively their equivalents can be run on iPads. After registration, the users can download iPad applications by means of the App Store using their Apple ID usernames. This way, applications can be upgraded, one account can be used for upgrading five iPads. This is similar to that of the android smartphones, in the case of which a Google ID is needed to be able to use the Market. Each iOS operating system is connected to an Apple ID, which can be used for the iTunes Store, iCloud and the App Store [4].

In the case more than one device is connected to the same Apple ID, then the formerly purchased applications can be download to other iOS devices free of charge. Furthermore, they can be set to automatically download the upgraded applications to each device. In addition to the Apple Store a huge collection of music, films, TV programs, books, podcasts and university courses are available for the iOS devices. The other huge repository is the Apple ID iCloud, which provides a storage capacity of

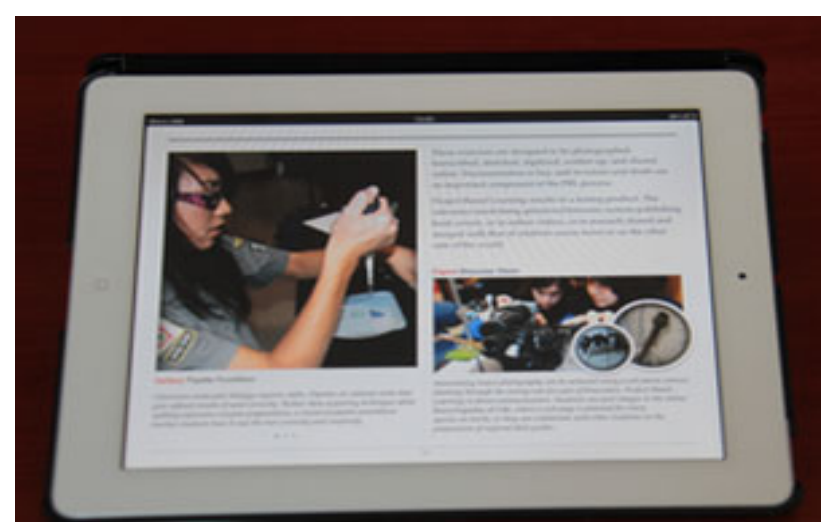

Figure 1. IPad 2, Source: Own figure

five GB for each user, which can also be used for security saving. This process can be automatically algorithmized, so if the given device is connected to a WiFi network, a security copy of its operation system is saved by the iCloud. Consequently, in case of any problem the security copy can be used. These devices can be synchronized with any PC by means of the iTunes application, which is suitable for storing downloaded programs, media content and security savings. E.g. the iPhoto, a part of the operation system, can easily be used on an iPad. When connected to Microsoft Windows, the system recognizes the iPad as a driver and the automatic play discussion panel pops up, by choosing "Importing videos and pictures" photos and videos can be imported by means of the Windows Photo Gallery application. iTunes synchronization can be carried out by means of an USB cable, or Wi$\mathrm{Fi}$, if the PC and the iOS (iPad) are connected to the same Wi-Fi network. The iPad applications of international importance are the following:

- the iPad as a source of information in addition to its GPS and navigation functions can be used by employees of United and Continental Airline

- the knowledge base and the connected 3D programs of anatomy can be used by employees of outpatient departments, hospitals, certain diagnostic measurements are also supported

- by employee of labour market enterprises

\section{Using IPADs in teaching and learning}

The adaptation of iPads in education is still in its infancy except for a few developed countries. Their application in education can be realized by means of two methods:

- iPads are distributed to the students before classes, prepared for performing a given task, then they are collected when the class is over. This way the iPad devices can be fully controlled in the school learning environment. The Apple provides a solution for such application: the so called Bretford PowerSync Case (See Figure 2) which can store, upload and synchronize 30 iPads at the same time. This mechanism should be used when pupils/students require more teacher attention. In such a case the same programs, applications run on the iPad.

- The iPads are handed out to the pupils/students for individual use, either at class or after class. In this case each pupil/student has an iPad and an Apple ID of his/her own, and use them as a personal device. 
This approach requires a bit more school organization to synchronize the necessary programs and applications. This method can be useful as the pupils/students can learn the use of the device more quickly. This approach should be used in the case of students over 18.

In the following practical educational applications of iPads will be presented and categorized by task type. Electronic textbooks, auxiliary materials, classroom note taking, content and activity management, group work, pair work, online tasks and independent learning are to be used in classroom environments. The kno, inkling and dropbox programs support electronic course materials, while the elements, notes plus and iannotate pdf are used for note taking. The iStudiez pro and iTeacher Book program support activities, iWork and Quick office Pro HD are used for preparing documents, the SketchBook Pro, iMovie and Garageband applications are used for media management. In addition to independent learning, pair work is also supported by means of Skype for iPad, GoToMeeting, iThoughts HD or Share Board. The last can realize working on several iPads at the same time to be shown by means of a Wi-Fi device. In addition of general application, job specific programs can also be downloaded such as software supporting studies in Anatomy, Maths, Chemistry, Mechanics, and Electrical Engineering. The use of blackboard is on no secondary importance either. Figure 3 shows iPad learning management programs. And not neglected the possibility of using the blackboard program either (See figure 4) [5].

\section{D. iPad-related surveys, researches}

The statistical data concerning the use of iPads are primarily to be found in professional works and sources. A good example is the statistical data of US Abilene Christian University showing our laptop and iPad uses and frequencies, such as:

- $50 \%$ of the lecturers use the iPad every lesson, $84 \%$ of them regularly

- The efficiency rate of knowledge transfer has increased to $79 \%$ by means of the iPad

- A much more frequent use of the course material was characteristic when these devices were used [6].

In conclusion, it can be stated that the use of the iPad means a bigger experience for the lecturers of the institution, both from the viewpoint of lecturers and students. The devices are said to have been received positively by the students. This urged teachers to recognize the fact that this technology can be used in an efficient way at class. Other statistical data show that educational institutions all over the world are interested in the integration of mobile devices into the teaching-learning process.

In Hungary, a methodological experiment of novel approach was introduced in the academic year of 2011/12 by Károly Eszterházy College and the Teacher Training Primary School of the College. The device in the focus of the research is the iPad. The pupils and teachers of class 8c started the academic year in an electronic learning environment involving iPad table devices and a touchscreen interactive whiteboard.

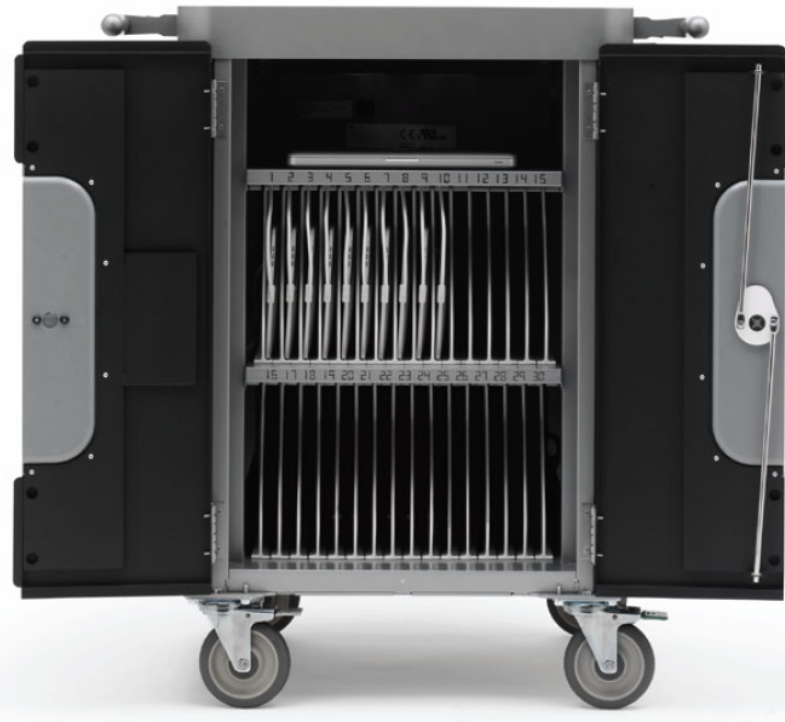

Figure 2. Bretford PowerSync for iPads, Source: Apple iOS Learning Solutions. 2011 cited 2011; Available from: http://images.apple.com/education/docs/

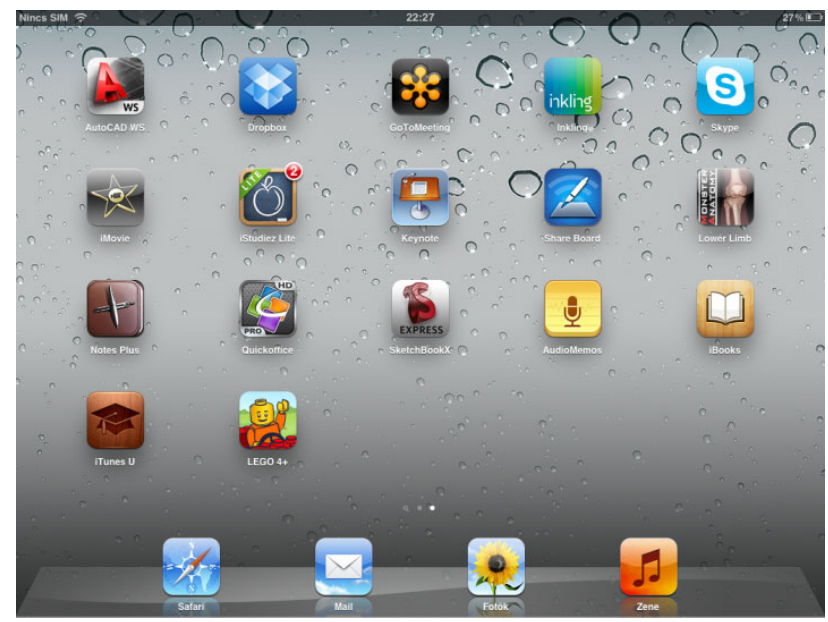

Figure 3. : iPad learning management programs, Source: Own figure

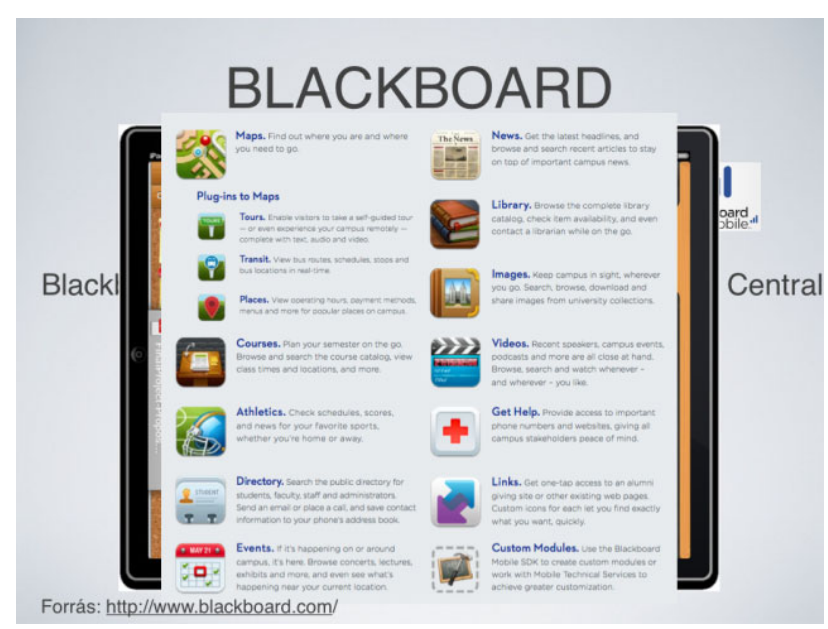

Figure 4. Blackboard application on IPAD, Source: Own figure 
PAPER

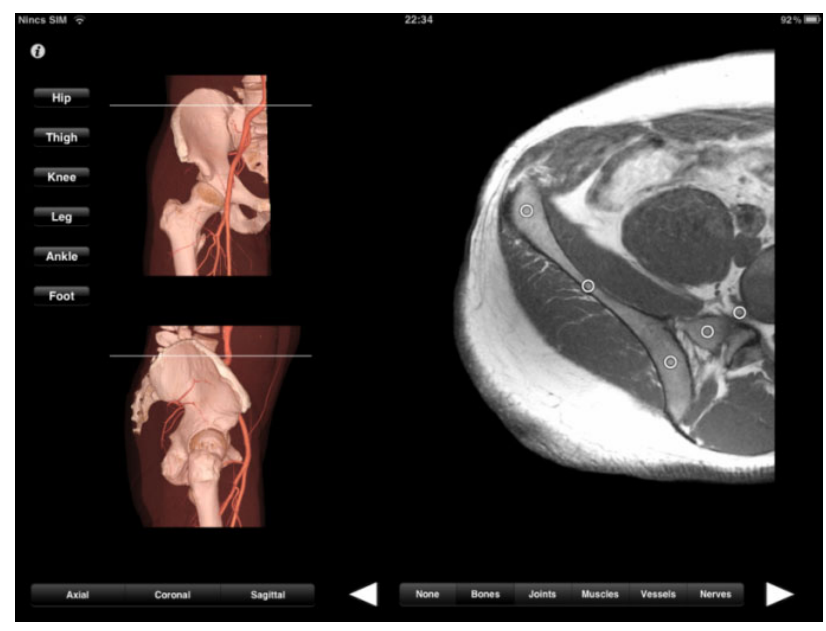

Figure 5. medicine application on IPAD, Source: Own figure

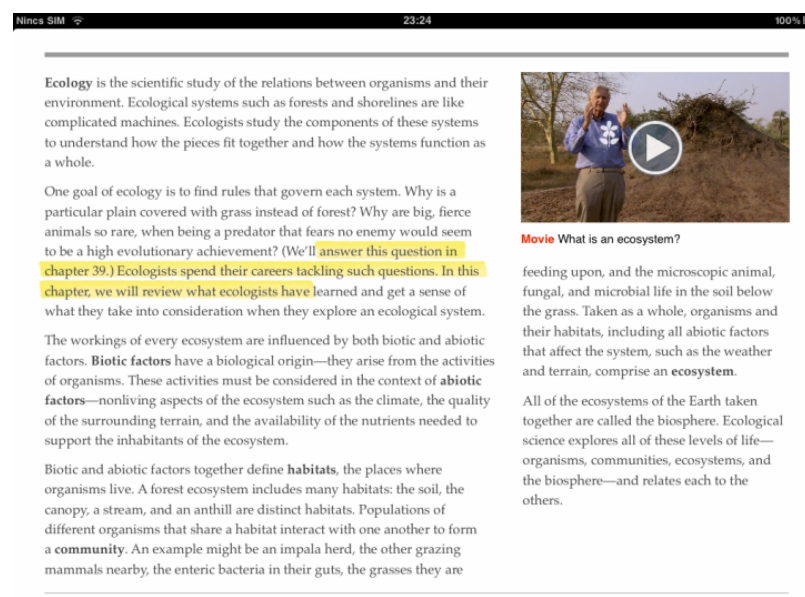

Figure 6. E-learning course on IPAD, Source: Own figure

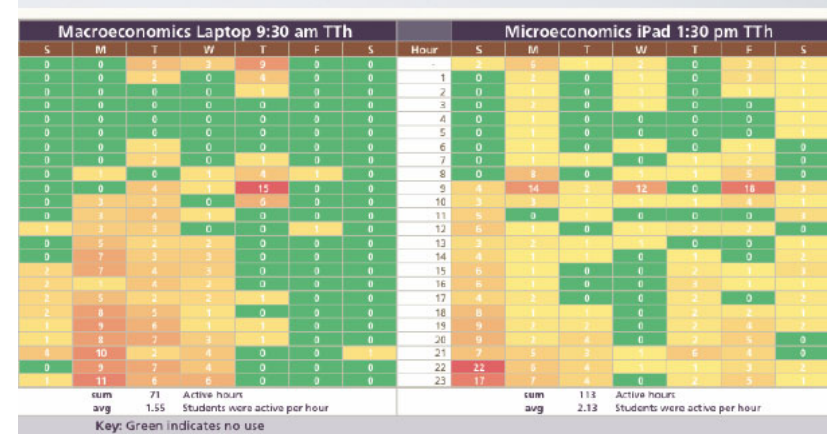

Figure 7. IPAD application in tertiary education, Source: Dr. Ian Sheppard, http://www.acu.edu/technology/mobilelearning/docu ments/research/ipad-or-ifad.pdf

The course materials - Hungarian Literature, History, Physics, Biology, Maths, Informatics, Geography and English Language - to be used by the table devices were provided by the Mozaik Publisher.

The process of knowledge transfer and acquisition is enriched by new interactive applications in addition to the course materials and the collections of activities in this up-to-date learning environment.

In the $2^{\text {nd }}$ stage of research each student of class $8 . \mathrm{D}$ and the members of faculty started the semester in a digital learning environment equipped with an iPad2 tablet and an interactive board The experiment aims to

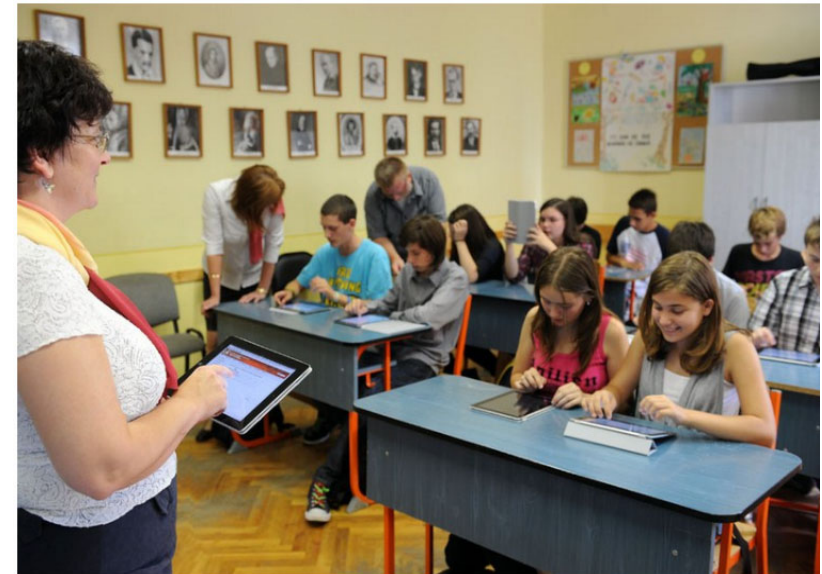

Figure 8. IPAD application in Primary School, Source: http://www.ipad.ektf.hu/?q=gallery

take advantage of iPad2 devices, which main element is the iBooks Author curriculum editor application.

Starting from this term the methodical emphasis is set on new, different bases. The main concept differs from the previous IT experiments, that not only a device is given to the staff, but a complete edition of textbooks in iBook form is provided both to students and teachers. The experiment is unique both in aspects of revolutionized curriculum and common access to the system.

But there is more to it than the curriculum conversion and digitalization. Taking advantage of iBook Author developer program, the traditional textbooks can be presented with interactive tasks, animations, and selfmonitoring interactive tests.

Some experienced teachers took part as mentors in the process and word as a catalysts they editorial work which was done by multiple developer teams, including graphic designers, and IT professionals.

The primal goal of experiment was to study the opportunities provided by the new learning environment. The observation and analysis helped mark the adequate and up to date learning trend.

\section{CONCLUSION}

Analyses carried out and experiences acquired so far suggest that classroom-based teaching and learning supported by iPads is more useful and efficient than otherwise. The iPad is an extremely innovative device when its proper services and applications are utilized. Naturally, when such a device is introduced in a school, appropriate technological background, staff and course materials need to be provided. The most recent iPad-based developments have just been released.

They are available here: http://events.apple.com.edge suite.net/1201oihbafvpihboijhpihbasdouhbasv/event/index .html [7]. Such a new development is the iBooks application, which automatically upgrades the content of the downloaded i-books in the e-library when the authors have changed the content. This program is only available on iPads and i-MACs.

A similar new application is the iBooks author only developed for MACs. Finally, iTunes U application is one of the latest programs being suitable for designing complete courses featuring audio, video, books, and other content by means of e-learning course design. 
PAPER

NeW LEARning Spaces? M-LeARning's, in PARTicular the iPAD’s Potentials in Education

Recently the latest, $3^{\text {rd }}$ generation iPad has been released. The new model offers better user experience, high resolution, 3.1MP screen, 5MP iSight optics and ultra high speed 4G LTE wireless technology.

All in all, the iPad tablet PCs are perfect for mLearning learning environments, which cannot only be used by the $\mathrm{Y}$ and $\mathrm{Z}$ generation learners, but by lecturers, educationalists as well for supporting learning in addition to maintaining motivation.

The iPad inspires creativity and various functions of mobile learning while becoming the students' favorite learning tool. Thanks to the pre-installed applications as AppStore and iTunes $U$ it supports collaborative work on Web 2.0 platform.

It also allows the students to be involved in sharing and editing the content and information. All this is possible regardless the time and space thanks to the iBook textbooks.

The latest generation of iPads opens a new horizon of learning both in formal and informal dimension, and build up a powerful learning potential.

\section{REFERENCES}

[1] Albert-László Barabási, Behálózva - a hálózatok új tudománya (Networked - the new science of networks) (Magyar Könyvklub, 2003., ISBN 963547895X)

[2] György Molnár, The requirements and development areas of the ICT aided learning environment, In: András Benedek (ed.): Digital pedagogy - Typotext Budapest 2008., pp. 225-255
[3] Piet Kommers, Piet A.M, ICT as explicit factor in the evolution of life-long learning. International journal of continuing engineering education and life-long learning, 20(1/2010), pp. 127-144

[4] György Molnár, Flashes or steady light? Or the potentials of developing networked learning, In: Miguel Baptista Nunes, Maggie McPherson (ed.): Proceedings of the IADIS International Conference e Learning, IADIS international conference E-learning 2011, Volume II. Rome, Italy, July 20-23, 2011, ISBN: 978-9728939-38-0, pp. 405-408

[5] György Molnár - András Benedek, The empirical analysis of a web 2.0-based learning platform, In: Constantin Paleologu, Constandinos Mavromoustakis, Marius Minea (ed.): ICCGI 2011, The Sixth International Multi-Conference on Computing in the Global Information Technology, Luxembourg, June 19-24, 2011., ISBN: 978-1-61208-008-6, pp. 56-62

[6] György Molnár - András Benedek and János Cz. Horváth, Jump over the shadow? From the traditional education to the non-typical one or the experiences of an electronic learning environment, In: Miguel Baptista Nunes, Maggie McPherson (ed.): Proceedings of the IADIS International Conference e Learning, IADIS international conference E-learning 2010, Freiburg, Germany, ISBN: 978-972-8939-17-5, pp. 243-247

[7] http://events.apple.com.edgesuite.net/1201oihbafvpihboijhpihbasd ouhbasv/event/index.html, last visit 14.05.2012

[8] http://www.ipad.ektf.hu/?q=gallery, last visit 14.08.2012

[9] http://www.acu.edu/technology/mobilelearning/documents/researc h/ipad-or-ifad.pdf, last visit 14.08.2012

\section{AUTHOR}

György Molnár Dr. is with Department of Technical Education, Budapest University of Technology and Economics, Budapest, Hungary

Received 30 November 2012. Published as resubmitted by the author 20 december 2012. 